Article

\title{
Impact of Transformer Turns Ratio on the Power Losses and Efficiency of the Wide Range Isolated Buck-Boost Converter for Photovoltaic Applications
}

\author{
Hamed Mashinchi Maheri, Dmitri Vinnikov *, Andrii Chub ${ }^{\mathbb{D}}$, Vadim Sidorov and \\ Elizaveta Liivik \\ Power Electronics Research Group, Department of Electrical Power Engineering and Mechatronics, \\ Tallinn University of Technology, 19086 Tallinn, Estonia; hamed.mashinchi@taltech.ee (H.M.M.); \\ andrii.chub@taltech.ee (A.C.); vasido@taltech.ee (V.S.); liisa.liivik@gmail.com (E.L.) \\ * Correspondence: dmitri.vinnikov@taltech.ee; Tel.: +372-620-3705
}

Received: 28 September 2020; Accepted: 26 October 2020; Published: 28 October 2020

check for updates

\begin{abstract}
In this paper, the impact of transformer turns ratio on the performance of the quasi-Z-source galvanically isolated DC-DC converters is studied. Embedded buck-boost functionality enables these converters to regulate the input voltage and load in a wide range, which makes them suitable for such demanding application as photovoltaic microconverters. The isolation transformer here plays a central role as its turns ratio defines the point of transition between the boost and buck modes and overall capability of the converter to regulate the input voltage in a wide range at high efficiency. The studied quasi-Z-source galvanically isolated DC-DC converter is benchmarked in terms of power loss of components and weighted power conversion efficiency for three different turns ratios of isolation transformer to achieve the best and optimized turns ratio lead to the efficient operation. Operation in a wide range of input voltage at high efficiency is the main criterion for assessing the effect of turns ratio on the efficiency of the converter. The proposed loss model and theoretical predictions of the efficiency were validated with the help of a $300 \mathrm{~W}$ experimental prototype of the photovoltaic microconverter based on the quasi-Z-source galvanically isolated DC-DC converter topology.
\end{abstract}

Keywords: quasi-Z-source converter; isolated buck-boost converter; power losses; efficiency; multimode control; photovoltaic power systems

\section{Introduction}

Isolated buck-boost converters (IBBCs) [1] are widely used in applications requiring regulation of the input or output voltage in a wide range at high efficiency along with the voltage level matching between the input and output ports. The photovoltaic (PV) microconverters [2-4], also known as the parallel-type DC power optimizers, are highly demanding examples of the IBBC application, which must ensure high performance at low realization complexity and cost. The range of input voltage regulation is the important performance metric of the PV microconverters (PVMICs), which enables the realization of the shade-tolerant Maximum Power Point Tracking (MPPT) using the P-V curve sweep technique [5]. Moreover, owing to the extended input voltage regulation capability, the PVMIC could be paired with different types of PV modules regardless of the number of cells and maximum power point voltage. On the other hand, the demands of high weighted efficiency and low production cost typically push designers to limit the input voltage regulation range below 1:2 to achieve higher efficiency values at a more affordable cost [6].

The first IBBC-based PVMIC was reported in 2014 under the name of hybrid series-resonant and PWM boost converter [2]. This converter could regulate the input voltage in a range from 15 
to $55 \mathrm{~V}$, utilizing the multimode control with a seamless transition between the modes. The input voltages below the nominal value were regulated by the boost switching stage embedded in the secondary side of the PVMIC. The leakage inductance of the secondary windings of the isolation transformer was used as a boost inductor, and the voltage gain was controlled by changing the duty cycle of a four-quadrant boost switch connected to the output terminals of the transformer. In the buck mode, the discussed PVMIC was controlled by the phase-shift modulation (PSM) at the resonant frequency. The integrated series resonant tank is formed by the leakage inductance of the transformer and capacitors of the voltage double rectifier (VDR). In the buck and boost operating modes, the IBBC PVMIC has demonstrated almost identical efficiency curves with the peak values well above $96.5 \%$ [2].

In the further modifications of the hybrid series resonant and PWM boost converter discussed in $[7,8]$, mainly the boost stage was simplified by using the concept of a boost rectifier, thus avoiding the need for the external four-quadrant boost switch. Thus, in [9] the diodes of the VDR were replaced by the active switches to perform the mixed task of synchronous rectification and voltage boost function. In $[8,10]$, two different approaches to full-bridge boost rectifier were studied, where either the one leg or the bottom pair of rectifier diodes were replaced by the active switches. However, the full-bridge boost rectifiers require more semiconductor devices as well as twice the turns ratio of the isolation transformer compared to the VDR configuration. Hence, they do not suit high input voltage step-up applications.

In contrast to the classical IBBC structure, where the boost and buck functions are performed either by different switching stages or by different converters, the quasi-Z-source (qZS) galvanically isolated DC-DC converter [11] offers an alternative approach to the IBBC, where a wide input voltage regulation range is realized in the front-end buck-boost inverter. Such an approach helps to avoid the use of a boost rectifier, thus reducing the design and control complexity of the PVMIC. The qZS IBBC combines the properties of the voltage- and current-fed converters, which enables ultimate control flexibility of the front-end inverter by utilizing all possible switching states, including the shoot-through (ST) and open states along with seamless transition between the operating modes. As a result, the unprecedented input voltage regulation range of 8 to $60 \mathrm{~V}$ achieved by the qZS IBBC in [11] has opened up new opportunities for the PVMIC, such as shade-tolerant (or global) maximum power point tracking (MPPT) and compatibility with different types of PV modules.

Like other IBBCs, the input voltage regulation range of the qZS IBBC is subdivided into two regions, i.e., the buck and boost regions. In the boost region, the input voltage is stepped up using the shoot-through pulse width modulation (ST-PWM) [11]. When the operating point moves to the buck region, the voltage is stepped down using various control methods ranging from the phase-shift modulation (PSM) [12] and variable frequency control [13] to asymmetrical PWM [12] and topology morphing control $[14,15]$. In the boundary between the boost and buck modes, the qZS IBBC operates as a series resonant converter in a nonregulated DC transformer (DCX) mode. In the classical design approach [11], dimensioning of the isolation transformer depends on the desired position of this boundary point (which is also known as a pass-through operation point), i.e., it defines transformer turns ratio along with selection of the optimal values of its leakage and magnetizing inductances. The turns ratio defines the gain of the converter in the DCX mode while the properly dimensioned leakage and magnetizing inductances ensure the quality factor of the resonant tank and soft switching performance, which are essential for achieving high values of efficiency.

The main aim of this paper is to evaluate the impact of the transformer turns ratio on the performance of the qZS IBBC-based PVMIC within the defined range of the maximum power point voltages, i.e., from 28 to $38 \mathrm{~V}$. In this input voltage range, the probability of converter operation is the highest when the shading is absent; therefore, the balanced performance in a wide power range becomes especially important. The weighted efficiency is used for the benchmarking of the converter designs. Changing the turns ratio of the isolation transformer is the simplest way to optimize performance of the qZS IBBC-based PVMIC. Previously, it was assumed that performance of this converter is the same in the boost and buck modes. This study verifies whether it is a correct assumption and how these modes 
could be rearranged otherwise to attain the best weighted average efficiency. Three case studies are benchmarked in terms of power loss components and weighted power conversion efficiency. Section 2 explains the operation and design principles of the converter. Section 3 describes the power loss model of the qZS IBBC, which can help to provide better understanding of power loss mechanisms of the converter in different operating modes. Next, the power losses and efficiency of the qZS IBBC are estimated and compared for three different turns ratios of the isolation transformer. The proposed loss model and theoretical predictions of the efficiency are validated by help of a $300 \mathrm{~W}$ experimental prototype of the qZS IBBC-based PVMIC in Section 4. Finally, the discussion on the obtained results and the conclusions are drawn in Sections 5 and 6, correspondingly.

\section{2. qZS IBBC-Based Photovoltaic Microconverter}

As was mentioned previously, the front-end inverter of qZS IBBC has an embedded buck-boost functionality; depending on the applied control method the inverter can either step down (Buck mode) or step up (Boost mode) the input voltage. The boundary operating point between the modes is usually selected according to the most probable maximum power point (MPP) voltage of the unshaded PV module, where the PVMIC is expected to operate at maximum power for most of the time [3]. For the modern 60-cell PV modules, such operating point could lie in the range from 28 to $33 \mathrm{~V}$, while for the 72-cell PV module, this range is shifted to $34-38 \mathrm{~V}$. Therefore, the design of a universal PVMIC with compatibility with 60- and 72-cell Si-based PV modules should consider the wide range of probable MPP voltages, which is typically as wide as $28-38 \mathrm{~V}$. To match the high demands on the performance of the PV power electronics, the PVMIC within this range should demonstrate the highest weighted power conversion efficiency regardless of the operating mode, which is a nontrivial task for a designer. The best results here could be achieved by the optimization of multimode control by proper selection of the turns ratio of the transformer in combination with the software-based efficiency optimization methods such as cycle-skipping modulation or topology-morphing control [14-17].

\subsection{Case Study qZS IBBC Based PVMIC}

The photovoltaic microconverter used in this study was originally proposed and validated in [11]. The power circuit topology and the main specifications of the PVMIC are presented in Figure 1 and Table 1, correspondingly. The operating power envelope of the converter is shown in Figure 2a, giving evidence of the converter's capability to operate at the full power of $300 \mathrm{~W}$ in the range from 28 to $38 \mathrm{~V}$. The baseline isolation transformer TX used in that study has the turns ratio of 6.1, which sets the pass-through operation point in the middle of the full-power voltage range, i.e., close to $33 \mathrm{~V}$. In that case, in the left half of that range, the PVMIC is controlled by the ST-PWM and boosts the input voltage to the value of the pass-through operation point. When the input voltage is higher than the threshold value, the converter starts operating in the buck mode using the PSM. The leakage inductance of the isolation transformer $L_{l k}$ is used as a resonant inductor, and during the active states (AS), its current resonates with the voltage of the parallel combination of the VDR capacitors $C_{1}$ and $C_{2}$. As the switching frequency equals the resonant frequency, the inverter switches and VDR diodes operate under the zero current switching conditions. To maintain the resonance, the values of VDR capacitors could be selected by:

$$
C_{1}=C_{2}=\frac{1}{8 L_{l k} \pi^{2} f_{S W}^{2}}
$$

where $f_{S W}$ is the converter switching frequency. Moreover, as the magnetizing current of the transformer recharges the parasitic output capacitances of the inverter switches, they all also feature the zero voltage switching. This effect is achieved by the proper trade-off between the values of magnetizing inductance and dead-time:

$$
L_{m} \leq \frac{T_{D} n^{2}}{8 f_{S W} C_{o s s}}
$$

where $C_{\text {oss }}$ is the parasitic output capacitance of the inverter switches $S_{1}-S_{4}$. 


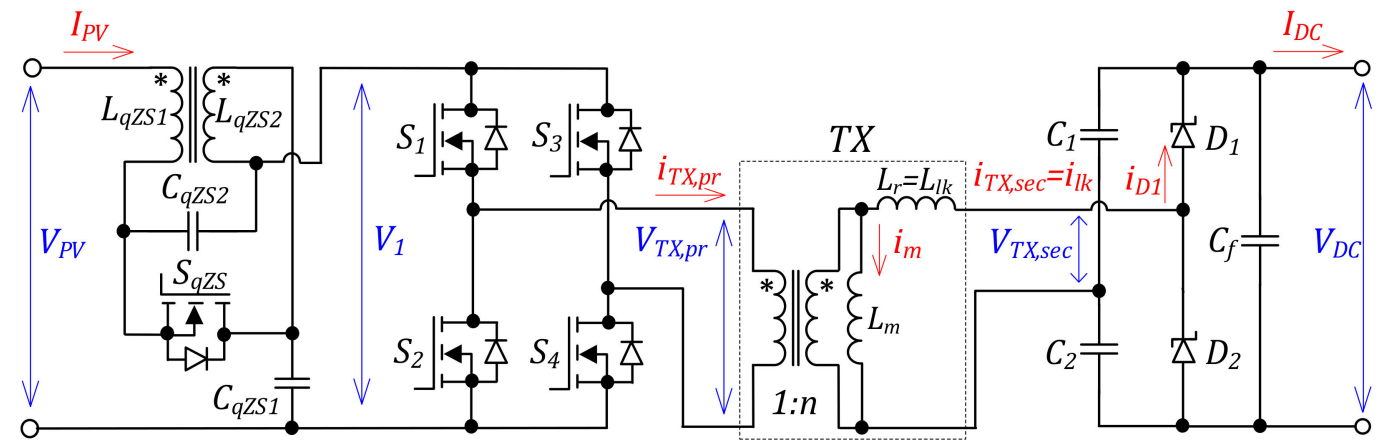

Figure 1. Power circuit topology of the case study qZS IBBC based performance metric of the PV microconverters (PVMIC).

Table 1. Specifications of the case study qZS IBBC based PVMIC.

\begin{tabular}{|c|c|c|}
\hline \multicolumn{3}{|c|}{ Operating Parameters } \\
\hline Parameter & Symbol & Range/Value \\
\hline MPPT voltage range & $V_{P V, M P P T}$ & $10-60 \mathrm{~V}$ \\
\hline Operating power range & $P_{P V}$ & $0-300 \mathrm{~W}$ \\
\hline Voltage range for maximum power & $V_{P V, \max P}$ & $28-38 \mathrm{~V}$ \\
\hline Switching frequency & $f_{S W}$ & $105 \mathrm{kHz}$ \\
\hline Dead-time of inverter switches & $T_{D}$ & 60 ns \\
\hline Output voltage & $V_{D C}$ & $400 \mathrm{~V}$ \\
\hline \multicolumn{3}{|c|}{ Passive Components } \\
\hline Component & Designator & Value \\
\hline \multirow{3}{*}{ Isolation transformer } & $n$ & 6.1 \\
\hline & $L_{m}$ & $1000 \mu \mathrm{H}$ \\
\hline & $L_{l k}$ & $28.8 \mu \mathrm{H}$ \\
\hline Coupled inductor & $L_{q Z S 1}, L_{q Z S 2}$ & $11 \mu \mathrm{H}$ \\
\hline \multirow{2}{*}{ qZS capacitors } & $C_{q Z S 1}$ & $18.5 \mu \mathrm{F}$ \\
\hline & $C_{q Z S 2}$ & $22.5 \mu \mathrm{F}$ \\
\hline VDR capacitors & $C_{1}, C_{2}$ & $43 \mathrm{nF}$ \\
\hline Output filtering capacitor & $C_{f}$ & $100 \mu \mathrm{F}$ \\
\hline \multicolumn{3}{|c|}{ Semiconductor Components } \\
\hline \multicolumn{2}{|l|}{ Component } & Part Number \\
\hline \multicolumn{2}{|c|}{$S_{1}-S_{4}$ and $S_{q Z S}$} & Fairchild FDMS86180 \\
\hline \multicolumn{2}{|c|}{ Rectifier diodes $D_{1}$ and $D_{2}$} & Cree C3D02060E \\
\hline
\end{tabular}

Idealized waveforms of IBBC for the boost and buck modes are shown in Figure 3. As the operation of the converter and the control strategies of the switches are different in each mode, analytical solutions of the component voltage and current are given separately for each operation mode. As the operation of the converter and the control strategies of the switches are different in each mode, analytical solutions of the component voltage and current are given separately for each operation mode. 


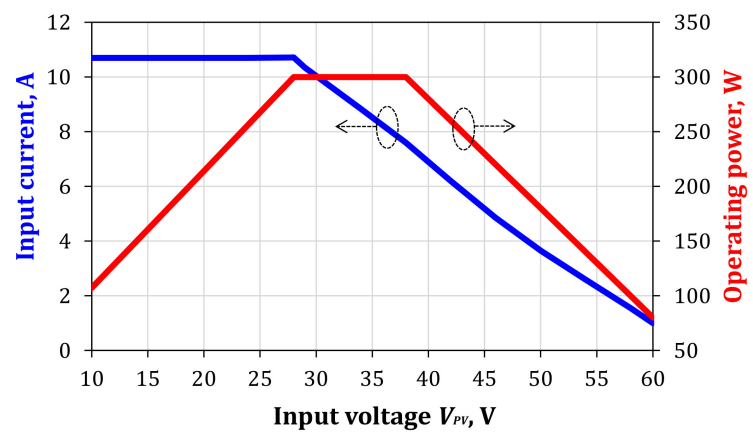

(a)

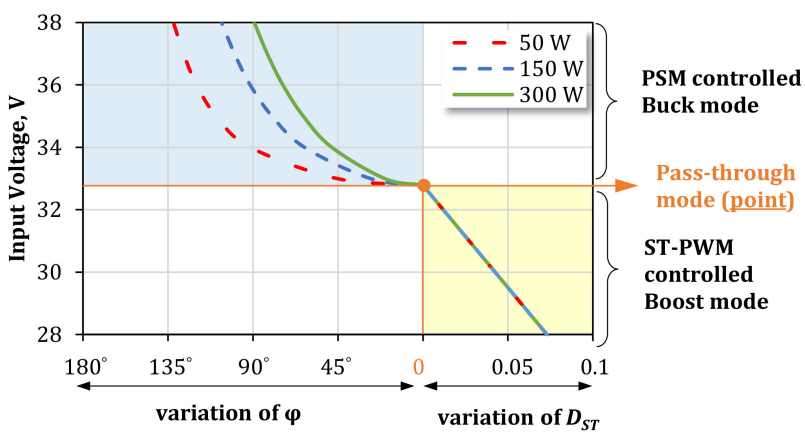

(b)

Figure 2. Operating power and input current profiles of the qZS IBBC based PVMIC (a) and its multimode control approach using the isolation transformer with turns ratio $n=6.1(\mathbf{b})$.

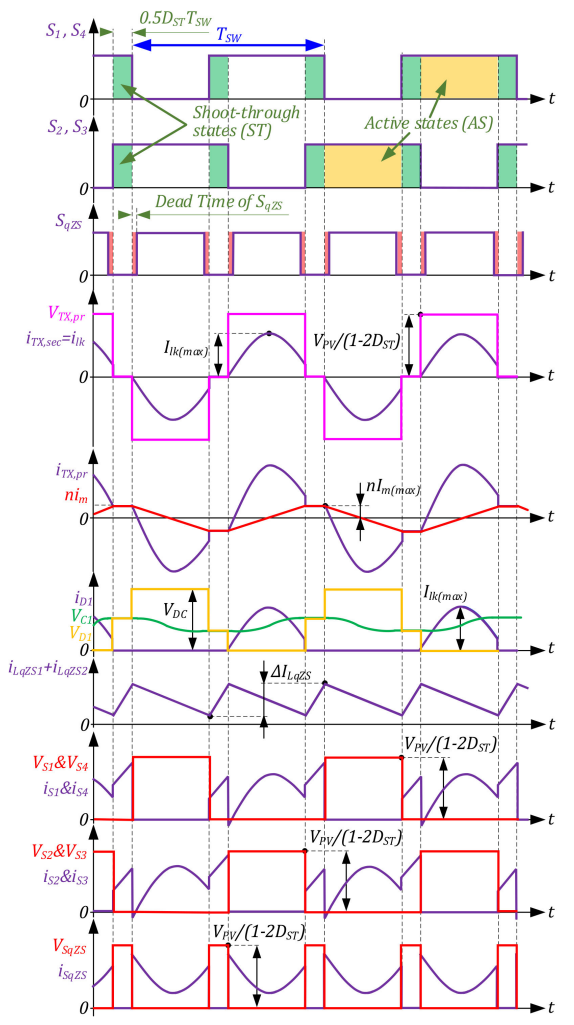

(a)

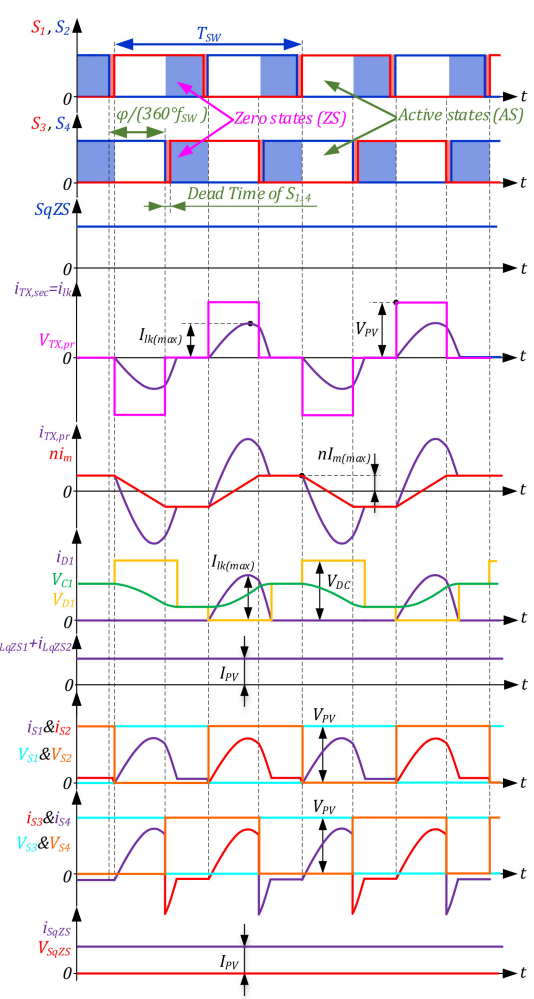

(b)

Figure 3. Operating waveforms of the qZS IBBC in the boost (a) and buck (b) operation modes. 


\subsection{Operation in the Boost Mode}

In the boost operating region, the converter is controlled by the ST-PWM at the resonant frequency (Figure 3a). The converter operates in the boost mode if the input voltage is below $V_{D C} / 2 n$. The DC voltage gain is regulated by the variation of the shoot-through duty cycle:

$$
G_{\text {boost }}=\frac{V_{D C}}{n V_{P V}}=\frac{1}{1-2 D_{S T}}
$$

where $D_{S T}$ is the cumulative duty cycle of the shoot-through states over the switching period $T_{S W}$ $\left(D_{S T}=t_{S t} / T_{S W}\right)$. The shoot-through states are generated by the cross-conduction of all switches of the inverter bridge, which occurs twice per switching period.

The piecewise waveforms of the leakage inductance current shown in Figure 3a can be defined as:

$$
i_{l k}(t)=\left\{\begin{array}{ll}
0 & S T \\
I_{l k(\max )} \sin \left(\omega_{r} t\right) & A S
\end{array},\right.
$$

where $I_{l k(\max )}$ is the maximum value of leakage inductance current, $S T$ is the shoot-through state, and $A S$ is the active state of the converter. The $I_{l k(\max )}$ is determined by Equation (5).

$$
I_{l k(\max )}=\frac{2 \pi I_{D C}}{\left[1-\cos \left(\pi\left(1-D_{S T}\right)\right)\right]}
$$

where $I_{D C}$ is the average value of the output current of the converter. According to Figure 3a the maximum value of the magnetizing current of the transformer is defined as follows:

$$
I_{m(\max )}=\frac{n V_{P V}\left(1-D_{S T}\right)}{4 L_{m} f_{S W}\left(1-2 D_{S T}\right)} .
$$

The piecewise functions of the primary and secondary currents of the isolation transformer are given by Equations (7) and (8).

$$
\begin{gathered}
i_{T X, p r}=\left\{\begin{array}{cc}
n i_{m} & S T \\
n\left(i_{l k}+i_{m}\right) & A S
\end{array} .\right. \\
i_{T X, \sec }=\left\{\begin{array}{cc}
0 & S T \\
i_{l k} & A S
\end{array} .\right.
\end{gathered}
$$

The amplitude voltage value of the primary winding of the isolation transformer is found by:

$$
V_{T X, p r}=\frac{V_{P V}}{\left(1-2 D_{S T}\right)} .
$$

The average current of the VDR diodes is obtained as follows:

$$
I_{D, a v}=\frac{1}{T} \int_{0}^{0.5\left(1-D_{S T}\right) T_{S W}} i_{D} d t=I_{D C} .
$$

The root mean square (RMS) current of the VDR diodes is defined by:

$$
I_{D, r m s}=\frac{I_{T X, \sec (r m s)}}{\sqrt{2}}
$$

where $I_{T X, s e c(r m s)}$ is the RMS current of the secondary windings of the isolation transformer. Considering the piecewise waveform of the switch current shown in Figure 3a, all the inverter switches conduct simultaneously during the shoot-through states. In the active states, one diagonal $\left(S_{1}\right.$ and $\left.S_{4}\right)$ is 
conducting during the positive half of the period and the other $\left(S_{2}\right.$ and $\left.S_{3}\right)$ for the negative half of the period. The switch current waveform could be described by Equations (12) and (13).

$$
\begin{aligned}
& i_{S 1}=i_{S 4}=\left\{\begin{array}{cc}
i_{L q Z S}+0.5 n i_{m} & S T \\
n\left(i_{l k}+i_{m}\right) & A S
\end{array},\right. \\
& i_{S 2}=i_{S 3}=\left\{\begin{array}{cc}
i_{L q Z S}-0.5 n i_{m} & S T \\
n\left(i_{l k}+i_{m}\right) & A S
\end{array},\right.
\end{aligned}
$$

where $i_{L q Z S}$ is the current of the qZS inductors obtained as follows:

$$
i_{L q Z S}(t)=\left\{\begin{array}{ll}
\frac{V_{P V}+V_{C q Z S 2}}{2 L_{q q S}} t+I_{P V}-\frac{\Delta I_{L q Z S}}{2} & S T \\
\frac{V_{P V}-V_{C q Z S 1}}{2 L_{q Z S}} t+I_{P V}+\frac{\Delta I_{L q Z S}}{2} & A S
\end{array},\right.
$$

where $V_{C q Z S 1}$ and $V_{C q Z S 2}$ are the voltages of qZS capacitors that could be calculated as:

$$
\begin{gathered}
V_{C q Z S 1}=\frac{\left(1-D_{S T}\right) V_{P V}}{1-2 D_{S T}}, \\
V_{C q Z S 2}=\frac{D_{S T} V_{P V}}{1-2 D_{S T}} .
\end{gathered}
$$

The current ripple of qZS inductors $\Delta I_{L q Z S}$ is calculated as:

$$
\Delta i_{L q Z S}=\frac{D_{S T} V_{P V}\left(1-D_{S T}\right)}{2 f_{S W} L_{q Z S}\left(1-2 D_{S T}\right)} .
$$

The current through the qZS switch is determined by:

$$
i_{S q Z S}= \begin{cases}0 & S T \\ 2 I_{P V}-i_{T X, p r} & A S\end{cases}
$$

The current of the qZS capacitors is defined by Equation (19).

$$
i_{C q Z S 1}=i_{C q Z S 2}= \begin{cases}-I_{P V} & S T \\ I_{P V}-i_{T X, p r} & A S\end{cases}
$$

The flux density swing of the transformer core could be determined based on the waveform of the magnetizing current during the active state. The peak-to-peak value of the flux density for the boost mode is defined by:

$$
\Delta B=\frac{V_{P V}\left(1-D_{S T}\right)}{2\left(1-2 D_{S T}\right) A_{c o r e} N_{p r}},
$$

where $A_{\text {core }}$ is the core area, and $N_{p r}$ is the number of primary winding turns.

The RMS current of the switches $S_{1}-S_{4}$, qZS switch, qZS inductor, VDR diodes, and the isolation transformer are defined from the corresponding time-domain equations. For example, the RMS current of the inverter switches could be obtained by:

$$
I_{S 1, r m s}=\ldots=I_{S 4, r m s}=\sqrt{\frac{1}{T_{S W}}\left(\int_{0}^{0.5 D_{S T} T_{S W}}\left(i_{L q Z S}+0.5 n i_{m}\right)^{2} d t+\int_{0}^{0.5\left(1-D_{S T}\right) T_{S W}}\left[n\left(i_{l k}+i_{m}\right)\right]^{2} d t\right)}
$$




\subsection{Operation in the Buck Mode}

In the buck mode, the converter is controlled by the PSM at the resonant frequency [12]. The converter operates in the buck mode if the input voltage is above $V_{D C} / 2 n$. As can be seen from Figure $3 \mathrm{~b}$, the switch $S_{q Z S}$ is always conducting, thus bypassing the qZS network. The output voltage is controlled by the variation of the phase shift angle $\varphi$ between the leading $\left(S_{1}\right.$ and $\left.S_{2}\right)$ and lagging $\left(S_{3}\right.$ and $S_{4}$ ) legs of the inverter bridge. As the resonant current is discontinuous, the control characteristic of the PVMIC in the buck mode depends strictly on the quality factor $Q$ of the resonant tank:

$$
G_{b u c k}=\frac{V_{D C}}{n V_{P V}}=0.5\left[A\left(\frac{2}{\pi Q}-1\right)+\sqrt{\left(\frac{2}{\pi Q}-1\right)^{2} A^{2}+A \frac{8}{\pi Q}}\right],
$$

where

$$
A=0.5-0.5 \cos \left[\pi\left(1-\frac{\varphi}{180}\right)\right], \text { and } Q=\frac{8 \pi f_{S W} L_{l k}}{R_{L}},
$$

where $R_{L}$ is the load resistance.

The current through the leakage inductance of the isolation transformer $I_{l k}$ has a piecewise waveform. In the active state, its maximum value is given by:

$$
I_{l k(\max )}=\frac{v_{T X, p r}\left(t_{i}\right) \cdot n-v_{C 1}\left(t_{i-1}\right)-\Psi_{D_{1}}\left(t_{i}\right) \cdot V_{D C}}{Z_{r}}
$$

where $v_{T X, p r}(t)$ is a piecewise-linear function of the primary voltage of the isolation transformer, $t_{i}$ is an $i$-th time instant, $\Psi_{D_{1}}(t)$ is a switching function of diode $D_{1}$, which can be written as:

$$
\Psi_{D_{1}}(t)= \begin{cases}1, & \text { if } D_{1} \text { is conducting } \\ 0, & \text { if } D_{1} \text { is reverse - biased. }\end{cases}
$$

For the buck mode, the amplitude voltage of the primary windings of the isolation transformer equals the input voltage. The voltage of the resonant capacitor could be defined by:

$$
v_{C 1}(t)=\frac{1}{C_{1}} \frac{d i_{l k}(t)}{d t}
$$

The maximum value of the magnetizing current is given by:

$$
I_{m(\max )}=\frac{n V_{P V}\left(180^{\circ}-\varphi\right)}{4 \cdot 180^{\circ} \cdot L_{m} f_{s}} .
$$

The primary and secondary currents of the isolation transformer are obtained as:

$$
\begin{gathered}
i_{T X, p r}(t)=n\left(i_{l k}(t)+i_{m}(t)\right), \\
i_{T X, \sec }(t)=i_{l k}(t) .
\end{gathered}
$$

According to Figure $3 b$, the current of the switches has a piecewise waveform that is obtained based on the current of the transformer as:

$$
\begin{aligned}
& i_{S 1}(t)=i_{S 2}(t)=n\left(i_{l k}(t)+i_{m}(t)\right), \\
& i_{S 3}(t)=i_{S 4}(t)=n\left(i_{l k}(t)+i_{m}(t)\right) .
\end{aligned}
$$


In the buck mode, the qZS switch conducts for the whole switching period, and the qZS network acts as an input filter. The currents through the qZS inductor and the qZS switch equal the average value of the input current:

$$
i_{\text {LqZS }}(t)=i_{S q Z S}(t)=I_{P V}
$$

The current of the qZS capacitors is defined by:

$$
i_{C q Z S 1}=i_{C q Z S 2}=I_{P V}-i_{T X, p r}
$$

The flux density swing of the transformer core depends on the variation of the magnetizing current. The magnetizing current has a symmetrical waveform that changes from peak to peak during active states (Figure 3b). Considering this, the peak-to-peak value of the core flux density is obtained as:

$$
\Delta B=\frac{V_{P V}\left(180^{\circ}-\varphi\right) T_{S W}}{4 \cdot 180^{\circ} \cdot A_{\text {core }} N_{p r}} .
$$

The voltage stresses of the inverter switches and the qZS switch during the off-state equal the amplitude voltage of the primary windings of the isolation transformer. This value is calculated by (10) for the boost mode and equals the input voltage for the buck mode. The RMS current of the inverter switches could be defined as:

$$
I_{S 1, r m s}=\ldots=I_{S 4, r m s}=\sqrt{\frac{1}{T_{S W}}\left(\int_{0}^{0.5 T_{S W}}\left[n\left(i_{l k}+i_{m}\right)\right]^{2} d t\right)} .
$$

\section{Impact of Transformer Turns Ratio on the Performance of qZS IBBC}

In this section, the impact of the transformer turns ratio on the performance of qZS IBBC is evaluated. For that purpose, two alternative isolation transformers with the turns ratios of 5.7 and 6.7 were chosen. As it is seen from Figure 4, the implementation of a transformer with $n_{2}=6.7$ (sample TX2 with specifications given in Table 2) shifts the pass-through operation point down to $30 \mathrm{~V}$, which results in the dominance of the buck mode over the boost mode in the case study voltage range of 28-38 V. When decreasing the turns ratio to $n_{1}=5.7$ (sample $T X 1$, see Table 2), the boost operating mode takes over two thirds of the voltage regulation range with the pass-through operation point located near $35 \mathrm{~V}$. As the performance of the qZS IBBC is different for the boost and buck modes, such adjustments in the turns ratio of the isolation transformer lead to changes in the power loss breakdown, which, in turn, impacts the efficiency of the converter. This section introduces the power loss model of the qZS IBBC, provides an insight into the power loss breakdown for the buck and boost operation regions, and evaluates the impact of the transformer turns ratio on the efficiency of the converter.

Table 2. Specifications of the alternative isolation transformers used in the study.

\begin{tabular}{cccc}
\hline Sample & Parameter & Designator & Value \\
\hline \multirow{4}{*}{$T X 1$} & Turns ratio & $n_{1}$ & 5.7 \\
& Magnetizing inductance & $L_{m, 1}$ & $814.7 \mu \mathrm{H}$ \\
& Leakage inductance & $L_{l k, 1}$ & $26.24 \mu \mathrm{H}$ \\
& Switching frequency & $f_{S W 1}$ & $107 \mathrm{kHz}$ \\
\hline \multirow{4}{*}{$T X 2$} & Turns ratio & $n_{2}$ & 6.7 \\
& Magnetizing inductance & $L_{m, 2}$ & $980.4 \mu \mathrm{H}$ \\
& Leakage inductance & $L_{l k, 2}$ & $33.8 \mu \mathrm{H}$ \\
& Switching frequency & $f_{S W 2}$ & $98 \mathrm{kHz}$ \\
\hline
\end{tabular}




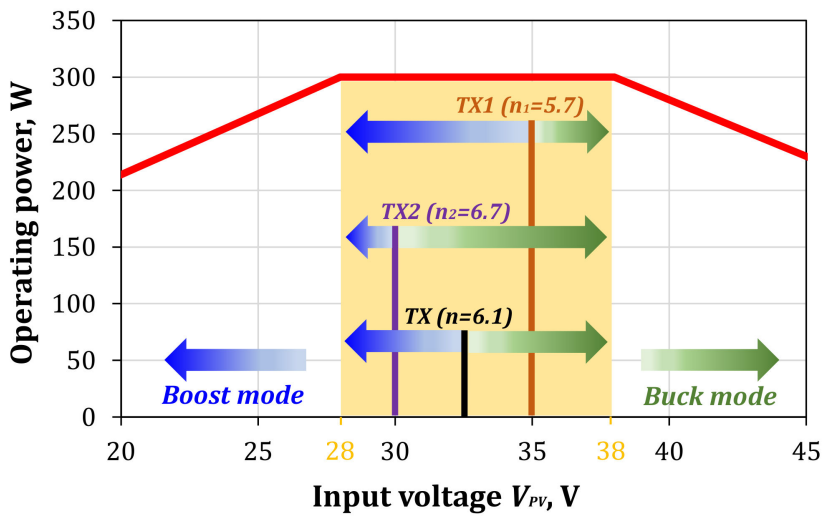

(a)

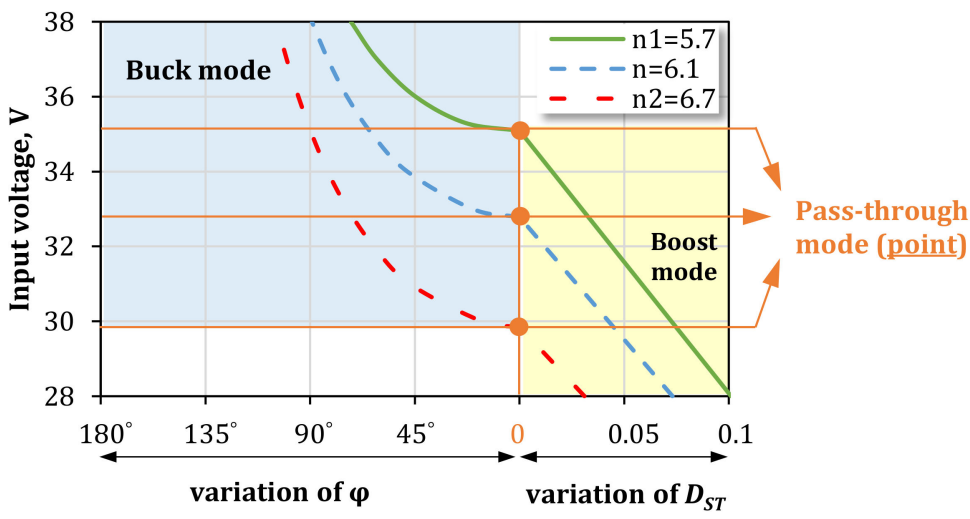

(b)

Figure 4. Impact of the turns ratio of the isolation transformer on the multimode control (a) and control variables (b) of qZS IBBC within the predefined voltage range: balanced buck-boost operation with the baseline transformer TX $(n=6.1)$, dominance of the boost mode with sample TX1 $\left(n_{1}=5.7\right)$, and dominance of the buck mode with sample TX2 $\left(n_{2}=6.7\right)$.

\subsection{Power Loss Model of the qZS IBBC}

The power losses of the qZS IBBC are broadly categorized as losses in magnetic components, i.e., qZS inductors and the isolation transformer and losses in semiconductors, i.e., switches and VDR diodes. The power losses in the switches are calculated as a sum of power losses of the inverter bridge transistors $S_{1}-S_{4}$ and the qZS switch $S_{q Z s}$. The power losses of the capacitors are considered only for qZS capacitors as the RMS current in input side is much higher than that in the output side. In addition, the power loss in the output filter capacitor $\left(C_{f}\right)$ is calculated since the equivalent series resistance (ESR) of this capacitor is high and affects the power losses. The power losses of the VDR film capacitors are neglected due to their low ESR. Next, the model of losses for each component of the qZS IBBC is presented. It helps in providing a better understanding of its operating principle and ways of further efficiency optimization for applications requiring a wide input voltage and load range.

Power losses of the switches, the MOSFETs in a given case, are divided into the conduction and switching losses. These losses are calculated based on the datasheet parameters and rms currents of the semiconductor components. The methods proposed in [18-20] are adopted for calculation of power losses of the MOSFETs and diodes. Conduction losses of MOSFETs mostly represent conduction losses in transistor:

$$
P_{S_{\_} c o n}=R_{D S(o n)} I_{S, r m S^{\prime}}^{2}
$$


where $R_{D S(o n)}$ is the drain-source resistance of MOSFET, and $I_{S, r m s}$ is the RMS current of the MOSFETs defined by (37). Switching losses of MOSFETs include the turn on/off losses and the reverse recovery losses of the body diode. The switching losses are:

$$
P_{S W}=\frac{1}{2} f_{S W} I_{S_{-} o n} V_{S}\left(t_{r}+t_{f u}\right)+Q_{r r} V_{S}+\frac{1}{2} f_{S} I_{S_{-} o f f} V_{S}\left(t_{f}+t_{r u}\right),
$$

where $t_{r}$ and $t_{f}$ are the current rise and fall time, respectively; $t_{f u}$ and $t_{r u}$ are the voltage fall and rise time, respectively; $Q_{r r}$ is the reverse-recovery charge; $f_{S W}$ is the switching frequency, and $V s$ is the voltage across the MOSFET during on and off state. $I_{S_{-} o n}$ is the switch current at the beginning of the turn-on transient and $I_{S_{-} \text {off }}$ is the switch current at the beginning of the turn-off transient.

Windings and core losses are the main sources of power dissipation in the isolation transformer and qZS inductors. Windings losses are calculated based on the equivalent resistance (ER) of the windings and the RMS current:

$$
P_{w}=R_{w} I_{T X, \sec (r m s)^{\prime}}^{2}
$$

where $R_{w}$ is the ER of the windings referred to the secondary windings and $I_{T X, \sec (r m s)}$ is the RMS value of the current of the secondary windings of the isolation transformer or the qZS inductor. The core losses could be calculated using the approach presented in [21,22]. Core losses are expressed by:

$$
P_{\text {core }}=\frac{v k_{i}(\Delta B)^{\beta-\alpha}}{T_{S W}} \sum_{m}\left|\frac{B_{m+1}-B_{m}}{t_{m+1}-t_{m}}\right|^{\alpha}\left(t_{m+1}-t_{m}\right),
$$

where $\Delta B$ is the peak-to-peak flux density, $v$ is the core volume, $k_{i}, \alpha$ and $\beta$ are the Steinmetz coefficients related to the core material, and $T_{S W}$ is the switching period.

As the VDR was built using Schottky barrier diodes, it has only conduction losses which can be calculated by (40) [18]:

$$
P_{D \_c o n}=V_{F} I_{D, a v}+R_{d} I_{D, r m s^{\prime}}^{2}
$$

where $V_{F}$ is the forward voltage drop, $R_{d}$ is the forward resistance, and $I_{D, a v}$ and $I_{D, r m s}$ are the average and RMS current of diode, respectively.

The power losses of qZS capacitors and $C_{f}$ is calculated based on the RMS current and ESR of capacitors as:

$$
P_{\text {Cap }}=r_{\text {Cap }} I_{\text {Cap, rms' }}^{2}
$$

where $r_{C a p}$ is the ESR of a capacitor and $I_{\text {Cap,rms }}$ is the RMS current of a capacitor. The RMS current of qZS capacitors could be calculated from (19) and (33) and RMS current of the output filter capacitor equals the RMS current of the diode $D_{1}$.

To improve the accuracy of power loss estimation, the ohmic losses in the printed circuit board (PCB) and external wiring in the input side are considered by using an equivalent ESR $r_{i n}$ and the average input current $I_{P V}$ :

$$
P_{\text {Wiring }}=r_{\text {in }} I_{P V}^{2}
$$

In the case of converter design based on the commercial off-the-shelf components, the specialized software [23-25] or design guidelines [26-28] provided by the manufacturer could be used. In addition, in case of availability, the simulation software such as PSIM could be used for calculation of power losses as this software has the capability to calculate the switching losses for switches [29-31]. On the other hand, the analytical approach provides a better understanding of the power loss mechanism and allows for faster optimized selection of components based on their datasheet parameters without the need for proprietary simulation software. 


\subsection{Estimation of Power Losses and Efficiency for Different Transformer Turns Ratios}

Using the power loss model presented above, the power losses and efficiency were estimated for three case study transformers within the full power range of the converter in three operation points, i.e., at 28, 33 and $38 \mathrm{~V}$. The main parameters used for the estimation are listed in Table 3. ER values of the magnetic components were measured by the LCR bridge HAMEG HM8118 at the switching frequency. The parameters related to the used MOSFETs, diodes, and transformer core were extracted from the datasheets for the given operation point $[32,33]$. The magnetic core losses were verified using Ferroxcube software design tool [34].

Table 3. Values used for estimation of power losses.

\begin{tabular}{|c|c|c|c|}
\hline Component & \multicolumn{2}{|c|}{ Parameter } & Value \\
\hline qZS inductor & \multicolumn{2}{|c|}{ Equivalent resistance $r_{L q Z S}$} & $7 \mathrm{~m} \Omega$ \\
\hline MOSFETS & \multicolumn{2}{|c|}{$\begin{array}{c}\text { Drain-source on-state resistance } R_{D S} \\
\text { Rise time } t_{r} \\
\text { Fall time } t_{f} \\
\text { Reverse-recovery charge } Q_{r r} \\
\text { Gate resistance } R_{G}\end{array}$} & $\begin{array}{l}3.7 \mathrm{~m} \Omega \\
12 \mathrm{~ns} \\
7 \mathrm{~ns} \\
109 \mathrm{nc} \\
3.5 \Omega\end{array}$ \\
\hline \multirow[t]{3}{*}{ Transformer } & $\begin{array}{r}\text { Core area } \\
\text { Core volun } \\
\text { Steinmetz coef } \\
\text { Steinmetz coef } \\
\text { Steinmetz coeff }\end{array}$ & $\begin{array}{l}\text { nt } \alpha \\
\text { nt } \beta \\
\text { nt } k_{i} \\
\quad T X(n=6.1)\end{array}$ & $\begin{array}{c}198 \mathrm{~mm}^{2} \\
27800 \mathrm{~mm}^{3} \\
1.045 \\
2.44 \\
0.0082 \mathrm{~W} / \mathrm{mm}^{3} \\
905.5 \mathrm{~m} \Omega\end{array}$ \\
\hline & \multirow[t]{2}{*}{ Equivalent resistance $R_{w}{ }^{*}$} & $\operatorname{TX} 1\left(n_{1}=6.7\right)$ & $720 \mathrm{~m} \Omega$ \\
\hline & & $\operatorname{TX2}\left(n_{2}=5.7\right)$ & $1.02 \Omega$ \\
\hline \multirow{2}{*}{ VDR diodes } & \multicolumn{2}{|c|}{ Forward voltage drop $V_{F}$} & $0.78 \mathrm{~V}$ \\
\hline & \multicolumn{2}{|c|}{ Forward resistance $R_{D}$} & $0.36 \Omega$ \\
\hline \multirow{3}{*}{ Capacitors } & \multirow{3}{*}{ ESR * } & $r_{C a p(C q z s 1)}$ & $7 \mathrm{~m} \Omega$ \\
\hline & & $r_{\text {Cap }(C q z s 2)}$ & $10 \mathrm{~m} \Omega$ \\
\hline & & $r_{C a p(C f)}$ & $300 \mathrm{~m} \Omega$ \\
\hline Wiring and PCB & \multicolumn{2}{|c|}{ Input-side ESR $r_{i n} *$} & $14 \mathrm{~m} \Omega$ \\
\hline
\end{tabular}

* Measured experimentally with HAMEG HM8118.

For all three case study transformers, the converter operates in the boost mode at $V_{P V}=28 \mathrm{~V}$ and in the buck mode at $V_{P V}=38 \mathrm{~V}$ regardless of the operating power. However, at the midrange point $V_{P V}$ $=33 \mathrm{~V}$, the operation mode of the converter depends strictly on the turns ratio of the transformer. Thus, for TX1 with $n_{1}=5.7$, the converter operates in the boost mode while for TX2 with $n_{2}=6.7$, the buck mode is still used at $V_{P V}=33 \mathrm{~V}$. In the case of a baseline transformer $T X$, the converter operates in the nonregulated DCX mode. The simulated primary voltage and current waveforms for the three case study transformers at $V_{P V}=33 \mathrm{~V}$ and operating power of $300 \mathrm{~W}$ are presented in Figure 5. 


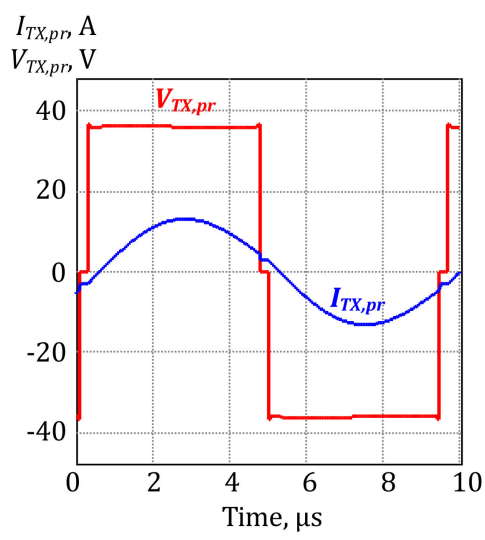

(a)

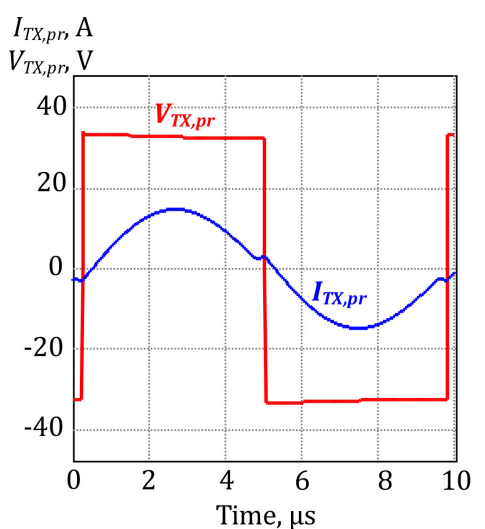

(b)

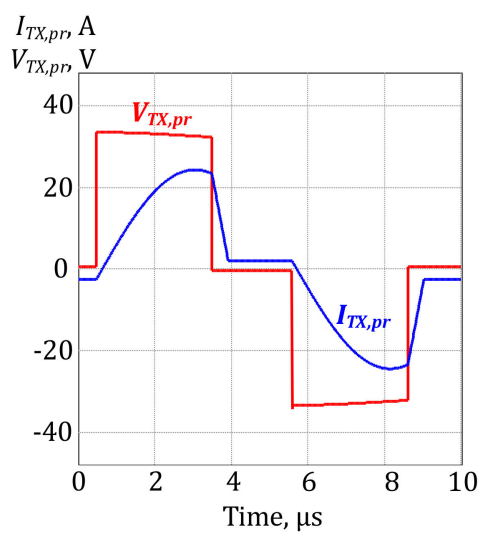

(c)

Figure 5. Simulated primary voltage and current waveforms of three key study isolation transformers at $V_{P V}=33 \mathrm{~V}$ and operating power of $300 \mathrm{~W}$ : (a) the boost mode with $D_{S T}=0.03$ for TX1 with $n_{1}=5.7$, (b) the DCX mode for the baseline transformer TX with $n=6.1$, and (c) the buck mode with $\varphi=73.8^{\circ}$ for TX2 with $n_{2}=6.7$.

\subsubsection{Power Loss Breakdown at Different Transformer Turns Ratios}

The breakdown of power losses of the converter for the three case study transformers at the input voltage of $33 \mathrm{~V}$ and operating power of $300 \mathrm{~W}$ is given in Figure 6. As can be seen, the conduction and windings losses dominate in the power losses for all the studied scenarios. Regarding the switching losses, the highest value was obtained for the transformer design TX1 with $n_{1}=5.7$ due to the hard-switching operation of the switches in the boost mode. The converter operates in the pass-through mode for the TX design with $n=6.1$, which results in the full soft-switching operation of semiconductors because the switching frequency equals the resonant frequency, i.e., zero switching losses (Figure 6b). For the design TX2 with $n_{2}=6.7$, the converter operates in the buck mode. Considering the waveforms in Figure $3 b$, in the buck mode, all of the switches (switches of leading and lagging legs) are turned on in the soft-switching conditions. The turn-off of the leading leg switches $S_{1}$ and $S_{2}$ is soft, but the lagging leg switches $S_{3}$ and $S_{4}$ are turned off in hard switching, which results in the switching losses lower than those in the boost mode. As can be seen from Figure 6, the windings losses of the isolation transformer are higher in the buck mode (Figure $6 c$ ) than in the boost or pass-through mode (Figure 6a,b, correspondingly). Two factors cause an increase in the windings losses. First, an increase in the number of turns in the secondary winding of the transformer results in higher winding resistance as a consequence of the increased influence of skin and proximity effects. Second, the RMS currents are increased due to the much shorter durations of the active states in the buck mode, which is caused by the dead zone of the control variable [11].

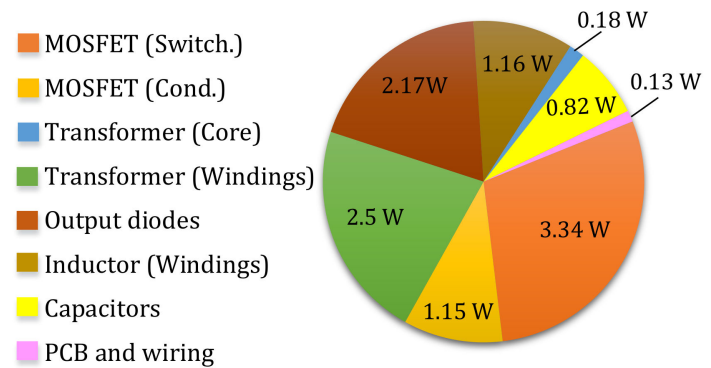

(a)

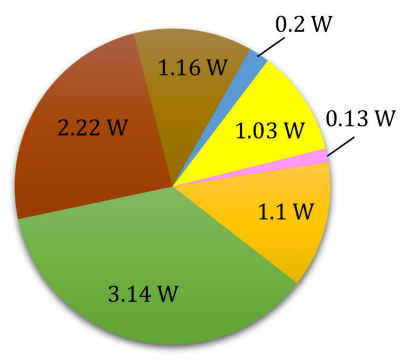

(b)

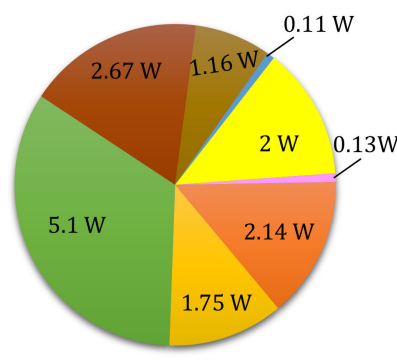

(c)

Figure 6. Distribution of power losses at the input power of $300 \mathrm{~W}$ for the turns ratio of: (a) $n_{1}=5.7$, (b) $n=6.1$, and (c) $n_{2}=6.7$. 
The validity of the comparison above could be substantiated by evaluating the RMS currents in the converter. According to the proposed model of power losses, most of the windings and conduction losses are proportional to the square values of the RMS currents. Figure 7 shows the variation of the RMS current of the inverter switches, the qZS switch, and the primary windings of the isolation transformer within the given input voltage operation range for the three compared isolation transformer designs. As can be appreciated from Figure 7, for all three turns ratios, the RMS current of the transformer primary windings and the inverter switches decreases with a slight slope in the boost mode. The trend is inverse for the buck mode, where the RMS current of the inverter switches and the isolation transformer is rising with an increase in the input voltage.

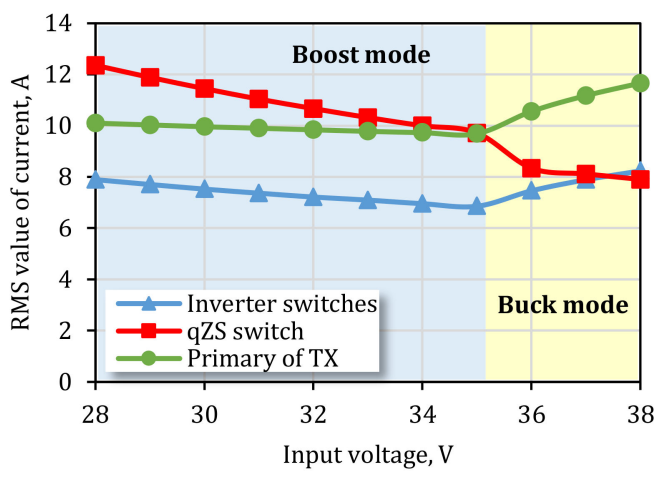

(a)

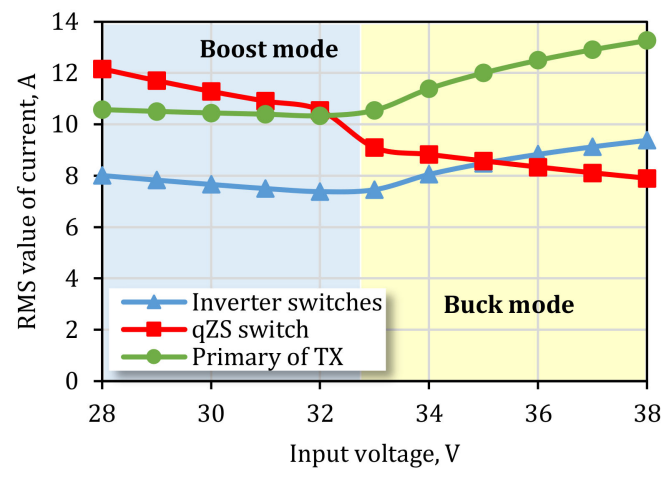

(b)

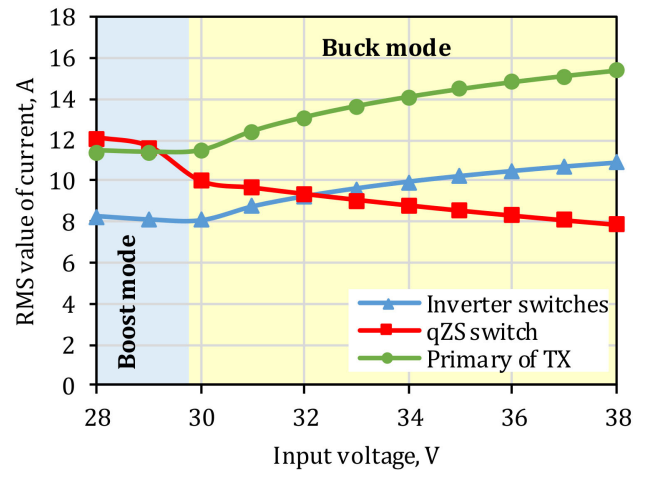

(c)

Figure 7. RMS current of inverter switches, qZS switch, and the primary windings of an isolation transformer: (a) $n_{1}=5.7,(\mathbf{b}) n=6.1$, and (c) $n_{2}=6.7$.

In the buck mode, the active state duty cycle is reduced considerably with an increase in the input voltage, which results in high RMS current of the switches and the transformer. The high value of the RMS current yields an increase in the windings and conduction losses. Hence, the duration of the active state has a considerable effect on the power losses. Windings losses in the qZS inductors are nearly the same for the three different turns ratios owing to the same value of the input voltage and current. Comparing conduction losses of the VDR diodes, the considered three turns ratios show that the losses are the highest in the buck mode, i.e., for $n_{2}=6.7$. Despite the same average output current, the RMS current of the VDR diodes in the buck mode is higher than that for the boost mode due to the shorter duration of the current pulses. A higher RMS current results in higher conduction losses in the VDR diodes in the buck mode. It can be concluded that the conduction losses of the VDR diodes follow a trend similar to the losses in the transformer for the same reasons. The power losses of capacitors for turns ratios of 5.7 and 6.1 are almost twice lower than that for $n_{2}=6.7$ as the buck mode operation with $n_{2}=6.7$ is associated with the highest value of RMS current in the circuit. Core losses of the isolation transformer, conduction losses of qZS inductors, PCB and wiring losses, as well as 
losses in the input side switches contribute a small fraction to the overall power loss in the converter for all three turns ratio values. Comparing overall power losses between the three different turns ratios shows that the converter has the lowest power losses of $8.9 \mathrm{~W}$ for the turns ratio of 6.1 and the highest at $12.9 \mathrm{~W}$ for $n_{2}=6.7$.

\subsubsection{Evaluation of Efficiency at Different Transformer Turns Ratios}

A comparison of estimated efficiency between three operation points for each of the selected turns ratios is shown in Figure 8. Figure 8a shows that the differences between the efficiency curves at the three input voltages for the case of $n_{1}=5.7$ are insignificant. This could be explained based on Figure 7 where the RMS currents of the switches and the isolation transformer show the smallest variation for $n_{1}$ $=5.7$. A smaller variation of the RMS current between the operation modes results in a small difference between the power loss and efficiency values. As a result, the efficiencies of the converter for the three different operation voltages are close to each other. For the turns ratio of 5.7, the converter operates in the boost mode at the input voltages of 28 and $33 \mathrm{~V}$. In the boost mode, higher input voltage results in lower RMS currents of the transformer and switches, which yields reduced power loss and increased efficiency at $V_{P V}=33 \mathrm{~V}$. As could be expected from Figure 7, the peak efficiency is achieved at $V_{P V}=33$ V. At light loads, the values of the efficiency are nearly the same at all three input voltages. Comparing the cases of $V_{P V}=28 \mathrm{~V}$ (boost mode) and $V_{P V}=33 \mathrm{~V}$ (buck mode), it could be concluded that the efficiency curves are nearly the same since the reduced RMS currents in the boost mode (reduced conduction and windings losses) are compensated with higher switching losses.

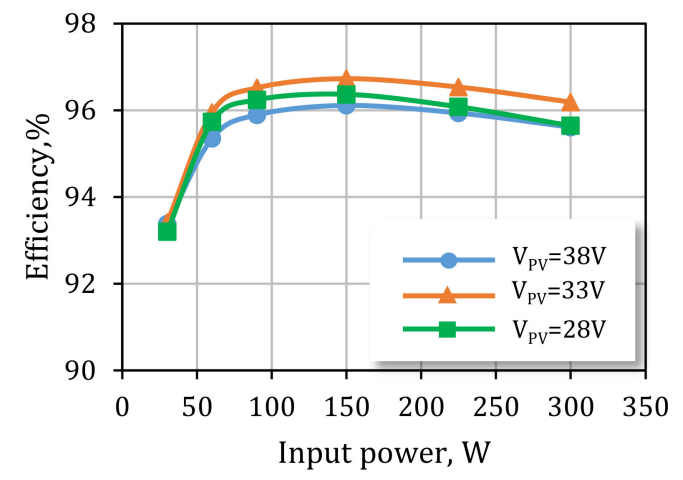

(a)

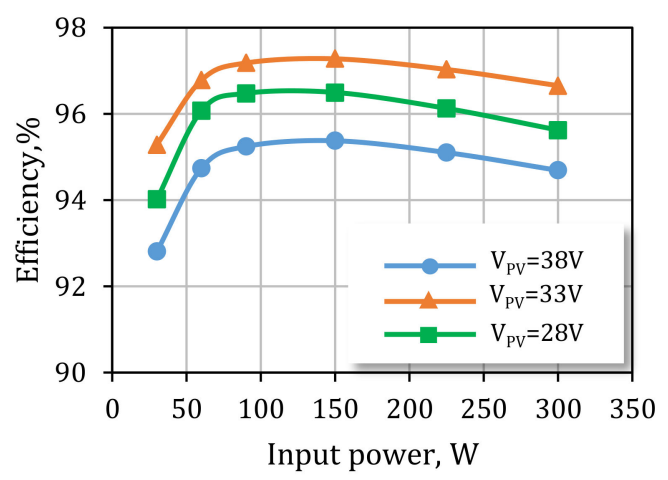

(b)

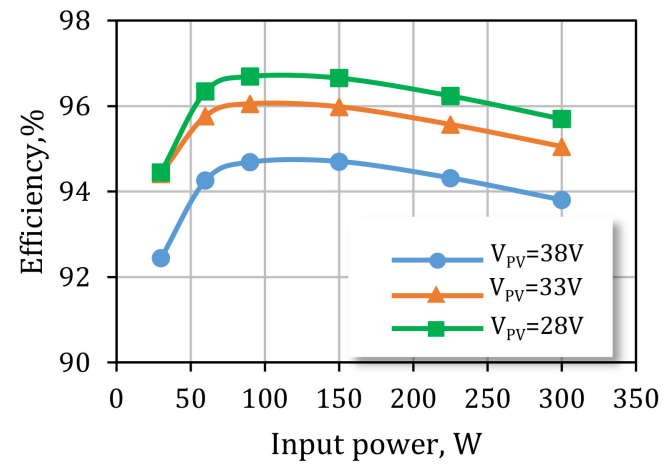

(c)

Figure 8. Comparison of estimated efficiencies of the converter for the turns ratio of: (a) $n_{1}=5.7$, (b) $n=6.1$, and (c) $n_{2}=6.7$.

As can be appreciated from Figure $8 b$, the converter features the highest efficiency at the input voltage of $33 \mathrm{~V}$ for $n=6.1$. At the input voltage of $38 \mathrm{~V}$, the converter operates in the buck mode and has the lowest efficiency among the three operation points. As can be seen from Figure $7 \mathrm{~b}$, the RMS currents at this point are high, which drives the conduction losses up even though the switching losses 
are low due to soft-switching in the buck mode. On the other hand, the operation in the boost mode at $V_{P V}=28 \mathrm{~V}$ is more efficient due to the low RMS current and associated windings and conduction losses and despite an increase in the switching losses. Compared to the transformer TX1 with $n_{1}=5.7$, the baseline design has a higher ER, making the windings losses even more impactful.

For the turns ratio of 6.7, the converter operates in the boost mode at $V_{P V}=28 \mathrm{~V}$ and in the buck mode at $V_{P V}=33 \mathrm{~V}$ and $V_{P V}=38 \mathrm{~V}$. As shown in Figure 8c, the estimated efficiency of the converter is the highest at the input voltage of $28 \mathrm{~V}$, and it is the lowest at $38 \mathrm{~V}$, which is in good agreement with the disposition of RMS current values in Figure 7c. It is worth mentioning that the transformer design with the highest turns ratio features the highest ER value, which is $42 \%$ higher than that for the transformer $T X 1$ with $n_{1}=5.7$.

For all three turns ratios, the converter efficiency in the boost mode is generally higher than that in the buck mode. Comparing the overall trend of the efficiency curves between the three turns ratios shows that for $n_{1}=5.7$, the difference between the efficiency curves in the operating points is the lowest, i.e., the converter performance is balanced in the given input voltage range. The highest efficiency was achieved at the input voltage of $33 \mathrm{~V}$ for $n=6.1$, where the converter operates in the vicinity of the pass-through mode, and the lowest at $V_{P V}=38 \mathrm{~V}$ with the turns ratio of 6.7, where the active state duty cycle is the lowest among all the operating points. The converter has the widest region of boost operation mode for $n_{1}=5.7$ and the narrowest for $n_{2}=6.7$.

Based on the above-presented analysis, it could be assumed that the turns ratio selection for the isolation transformer of the qZS based IBBC can determine the overall converter performance in a wide input voltage range. This converter average efficiency could be optimized by limiting its operation in the buck mode using a transformer with a turns ratio reduced in comparison to the baseline case. In the next chapter, this assumption is verified for the typical 60-cell Si-based PV modules that have the most probable range of operating voltage between 28 and $33 \mathrm{~V}$.

\section{Experimental Validation}

In this section, experimental results are given to verify the validity of the power loss model and the assumptions made based on the theoretical analysis. A $300 \mathrm{~W}$ prototype (Figure 9) was assembled based on the main schematics of the IBBC shown in Figure 1. The main specifications and types of semiconductor components used in the prototype are listed in Table 1. The converter was tested within the input voltage range of 28 to $38 \mathrm{~V}$, which was provided by the solar array simulator EA PSI9080-60. The output voltage was regulated to $400 \mathrm{~V}$. The converter was controlled by the microcontroller STM32F334R8T6 utilizing Cortex-M4 core. The power conversion efficiency was measured by the help of a precision power analyzer Yokogawa WT1800 in three operation points for the three turns ratios of the isolation transformer (Figure 10).

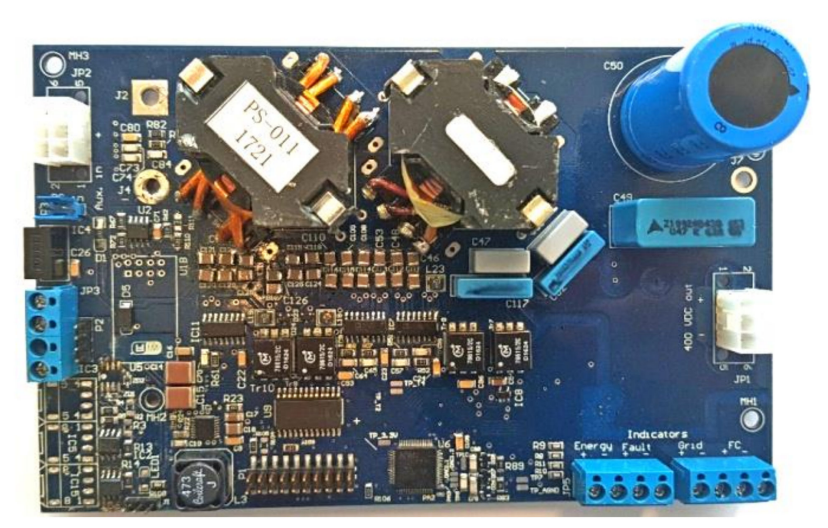

Figure 9. General view of the $300 \mathrm{~W}$ experimental prototype of the qZS IBBC based PVMIC. 


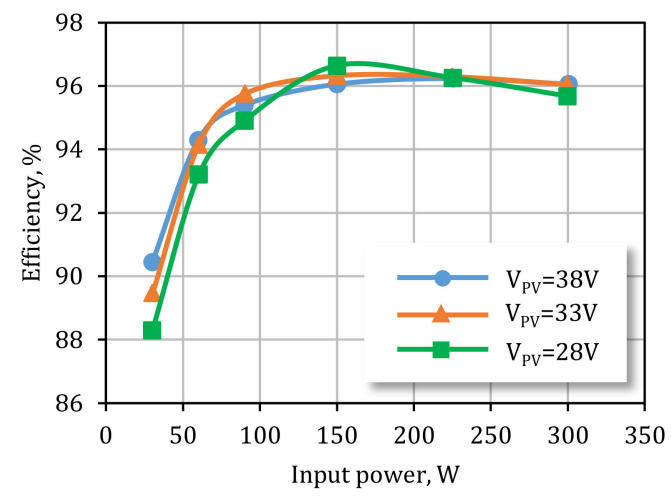

(a)

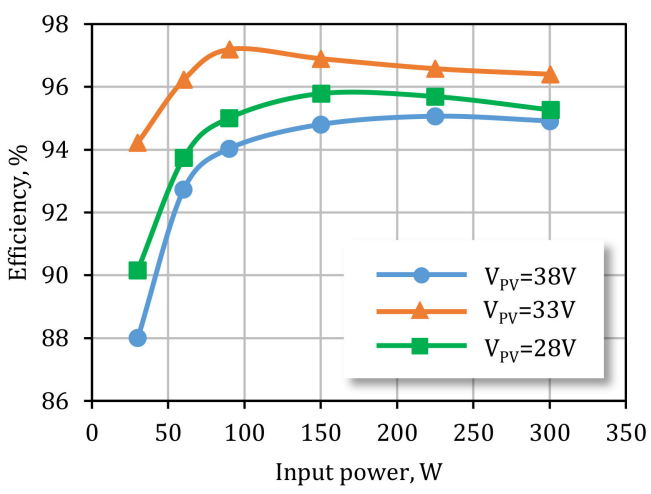

(b)

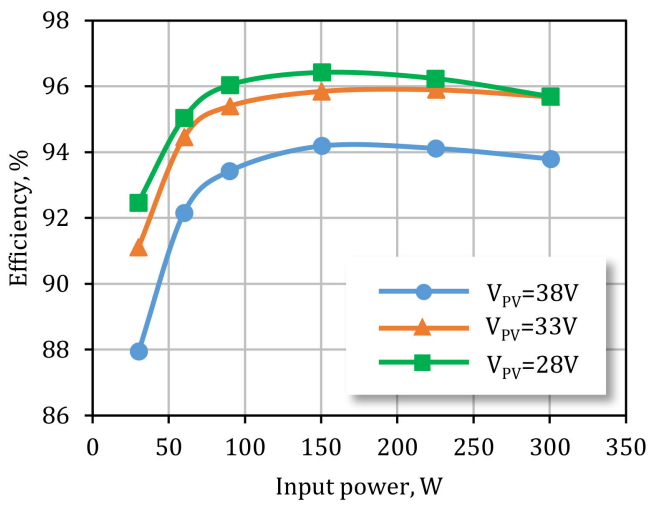

(c)

Figure 10. Comparison of measured efficiency of the converter for the turns ratio of: (a) $n_{1}=5.7$, (b) $n=6.1$, and (c) $n_{2}=6.7$.

Comparing the curves in Figure 10 to the estimated results in Figure 8, the measured efficiency follows the same trend as the estimated efficiency. This confirms the assumption that the multimode control in the presented case study should be realized with the dominance of the boost mode, i.e., the application of transformers with turns ratio of 5.7 and 6.1 is preferable over the one with 6.7. The deviations between the estimated and experimental results are caused by the thermal effects not considered in the model: copper windings increase their resistance with temperature $(0.38 \%$ per Kelvin); on-state drain-source resistance changes with temperature ( $0.44 \%$ per Kelvin); tolerance margin of datasheet parameters (for ex., 33\% difference between typical and maximum on-state drain-source resistance). All these uncertainties create differences between the theory and calculation, which does not exceed $0.5 \%$ at the full power. Even though there are still differences between calculated and measured efficiency values, the power loss model provides accurate qualitative predictions of transformer turns ratio influence on the average weighted efficiency.

The given experimental and theoretical results show that the turns ratio of the transformer affects the efficiency of the converter considerably. To achieve good performance with high efficiency in a wide input voltage range, the best turns ratio should be selected. The weighted California Energy Commission (CEC) efficiency in different operation points for all three turns ratios could be analyzed to select the best turns ratio.

The impact of transformer turns ratio on the weighted CEC efficiency for the case study converter is shown in Table 4. The weighted CEC efficiency is one of the most used parameters for the efficiency benchmarking of PV converters. It is obtained based on efficiency measurements at six power levels relative to the rated converter power. This benchmarking criterion is generally more useful than the converter peak efficiency because it measures converter performance across the range of the input power and considers weighting factors representing the probability of converter operation at a given 
power level. The weighted CEC efficiency gives a better idea about the PV converter operating profile over the course of a day. It could be calculated by:

$$
\eta_{C E C}=0.04 \eta_{10 \%}+0.05 \eta_{20 \%}+0.12 \eta_{30 \%}+0.21 \eta_{50 \%}+0.53 \eta_{75 \%}+0.05 \eta_{100 \%}
$$

where $\eta_{X \%}$ is the efficiency of the converter for $X$ percentage of full power in a given operating power range. For the maximum power of $300 \mathrm{~W}$, the efficiency at $75 \%$ of the full power, i.e., at $225 \mathrm{~W}$, affects the weighted CEC efficiency the most. Table 4 presents the estimated and measured weighted CEC efficiency values and corresponding calculation results for average weighted CEC efficiency for three operating points and three transformer designs.

Table 4. Evaluation of the transformer turns ratio impact on weighted and average weighted California Energy Commission (CEC) efficiency.

\begin{tabular}{|c|c|c|c|c|c|c|}
\hline \multirow{2}{*}{$n$} & \multirow{2}{*}{$V_{P V}(\mathrm{~V})$} & \multirow{2}{*}{ Mode } & \multicolumn{2}{|c|}{ Weighted CEC eff. (\%) } & \multicolumn{2}{|c|}{ Average Weighted CEC eff. (\%) } \\
\hline & & & Theoretical & Experimental & Theoretical & Experimental \\
\hline \multirow{3}{*}{5.7} & 28 & Boost & 96 & 95.7 & \multirow{3}{*}{96.1} & \multirow{3}{*}{95.8} \\
\hline & 33 & Boost & 96.4 & 95.8 & & \\
\hline & 38 & Buck & 95.8 & 95.8 & & \\
\hline \multirow{3}{*}{6.1} & 28 & Boost & 95.9 & 95.3 & \multirow{3}{*}{96} & \multirow{3}{*}{95.4} \\
\hline & 33 & Boundary & 97 & 96.5 & & \\
\hline & 38 & Buck & 95 & 94.5 & & \\
\hline \multirow{3}{*}{6.7} & 28 & Boost & 96.3 & 96 & \multirow{3}{*}{95.4} & \multirow{3}{*}{95.1} \\
\hline & 33 & Buck & 95.7 & 95.6 & & \\
\hline & 38 & Buck & 94.3 & 93.7 & & \\
\hline
\end{tabular}

As can be appreciated from Table 4, the lowest value of the weighted CEC efficiency is observed at the input voltage of $38 \mathrm{~V}$ for all studied transformers. For the turns ratio of 6.7 , the weighted CEC efficiency is the highest at the input voltage of $28 \mathrm{~V}$ and the lowest in the buck mode at the input voltage of $38 \mathrm{~V}$. The analysis of the measured and estimated efficiency values confirms the theoretical assumptions drawn from Figure 8 regarding dispositions of the efficiency curves relative to each other for all three transformer designs. The average weighted CEC efficiency was calculated for each of the turns ratios based on the measured and estimated weighted CEC efficiency values for the operating points of 28, 33, and $38 \mathrm{~V}$. As can be seen from Table 4, the dominance of the boost mode in the target input voltage range of 28 to $38 \mathrm{~V}$ (for turns ratio of 5.7 and 6.1) provides better average weighted efficiency than that in the case of turns ratio of 6.7 , where the buck mode extends across two thirds of the input voltage range. This confirms the assumption that there is an optimal arrangement of the buck and boost mode across the target input voltage range that provides the best average weighted CEC efficiency. Therefore, selection of the transformer turns ratio is of paramount importance for the balanced operation of the qZS IBBC.

\section{Discussions}

In this section, a discussion is presented based on the theoretical and experimental results. Our analysis of the power losses shows that the copper losses of the transformer are dominant. They are the highest in the buck mode owing to the short duration of the active state and, consequently, high RMS currents. The switching losses are the highest in the boost mode. The soft turn-on of all switches and soft turn-off of two of them in the buck mode results in the switching losses lower than in the boost mode. Zero switching losses are achieved in the pass-through point at the turns ratio of 6.1. At this point, the converter operates in the DCX mode without any switching losses in semiconductors. In the considered full-power input voltage range, the converter features the lowest efficiency in the 
buck mode at the input voltage of $38 \mathrm{~V}$ for all considered turns ratios. This is caused by the high RMS currents and, consequently, excessive conduction and transformer windings losses.

The peak efficiency was reached at the pass-through point for the turns ratio of 6.1, both in the calculations and experiments. For this turns ratio, the experimental efficiency in the boost mode at $28 \mathrm{~V}$ is up to $2 \%$ higher than that for the buck mode at $38 \mathrm{~V}$, i.e., in the operating point at equal distances from the pass-through operating point. The efficiency decreases for the turns ratios lower and higher than 6.1. For the turns ratio of 6.7, the highest efficiency can be achieved in the boost mode but the region of boost operation is narrow. As operation in the pass-through point at $n=6.1$ can be achieved in a narrow input voltage window, it is impossible to limit operation only to that highly-efficient unregulated DCX mode.

The converter was benchmarked with three transformer designs in terms of weighted and weighted average CEC efficiency. The provided comparison of the experimental and the theoretical values of the converter efficiency confirmed the validity of the theoretical analysis. It was found that the turns ratio of 5.7 provides the most balanced performance in terms of the weighted average CEC efficiency. On the other hand, the converter performance is nearly the same for the turns ratio of 6.1, while the efficiency in the input voltage range of 28 to $33 \mathrm{~V}$ is higher than that for the turns ratio of 5.7. In terms of the weighted average CEC efficiency, these two cases differ by only $0.3 \%$ in practice. Even though the converter is compatible with both 60- and 72-cell Si-based PV modules, it is much more likely to be coupled with the former type. Hence, the majority of installations will benefit from the design with the turns ratio of 6.1 even though the converter performance deteriorates slightly at voltages above $33 \mathrm{~V}$ when compared to the turns ratio of 5.7. The design with the turns ratio of 6.1 is still acceptable for 72 -cell PV modules as its full power efficiency at $38 \mathrm{~V}$ is only $0.5 \%$ lower than that for the turns ratio of 5.7. Even though the turns ratio of 6.7 can optimize the converter operation with 72-cell PV modules, this design is not likely to be adopted in practice where a universal converter with balanced performance is needed.

\section{Conclusions}

Power losses and efficiency of the galvanically isolated full-bridge series resonant quasi-Z-source buck-boost dc-dc converter has been studied for different turns ratios of the isolation transformer. The analysis was based on the proposed model of power losses. In the specified full-power input voltage range from 28 to $38 \mathrm{~V}$, the pass-through operating point changes its position with a change of the turns ratio. In this range, the converter operates mostly in the boost mode with the turns ratio of 5.7 and in the buck mode with 6.7. These modes cover the full-power input voltage range equally with the baseline turns ratio of 6.1. For a given input voltage range the switching losses are highest in the boost mode. The conduction and windings losses are highest in the buck mode. For all of three turns ratios the highest efficiency is achieved in pass-through operating point at the turns ratio of 6.1. Since limiting the operation region of the converter to this point is not reasonable, the operation in the boost mode is superior to that in the buck mode owing to the higher efficiency. The highest weighted efficiency is achieved for the turns ratio of 5.7 and 6.1. Considering the efficiency and the weighted efficiency, the converter shows the balanced operation for the turns ratio of 6.1 with a best compatibility with 60 - and 72 cell PV modules.

Author Contributions: Conceptualization, A.C. and D.V.; methodology, H.M.M. and A.C.; software, H.M.M. and V.S.; validation, V.S., E.L., and H.M.M.; formal analysis, V.S. and H.M.M.; investigation, H.M.M., E.L., and D.V.; resources, D.V. and A.C.; data curation, A.C. and H.M.M.; writing-original draft preparation, H.M.M. and D.V.; writing-review and editing, A.C., H.M.M., and D.V.; visualization, V.S., E.L., and H.M.M.; supervision, A.C. and D.V.; project administration, D.V.; funding acquisition, D.V. All authors have read and agreed to the published version of the manuscript.

Funding: This research was supported in part by the Estonian Research Council (grant PUT1443) and in part by the Estonian Centre of Excellence in Zero Energy and Resource Efficient Smart Buildings and Districts (ZEBE), grant 2014-2020.4.01.15-0016 funded by the European Regional Development Fund.

Conflicts of Interest: The authors declare no conflict of interest. 


\section{References}

1. Yao, C.; Ruan, X.; Wang, X.; Tse, C.K. Isolated Buck-Boost DC/DC Converters Suitable for Wide Input-Voltage Range. IEEE Trans. Power Electron. 2011, 26, 2599-2613. [CrossRef]

2. LaBella, T.; Lai, J. A Hybrid Resonant Converter Utilizing a Bidirectional GaN AC Switch for High-Efficiency PV Applications. IEEE Trans. Ind. Appl. 2014, 50, 3468-3475. [CrossRef]

3. Chub, A.; Vinnikov, D.; Kosenko, R.; Liivik, E. Wide Input Voltage Range Photovoltaic Microconverter With Reconfigurable Buck-Boost Switching Stage. IEEE Trans. Ind. Electron. 2017, 64, 5974-5983. [CrossRef]

4. Vinnikov, D.; Chub, A.; Zinchenko, D.; Sidorov, V.; Malinowski, M.; Bayhan, S. Topology-Morphing Photovoltaic Microconverter with Wide MPPT Voltage Window and Post-Fault Operation Capability. IEEE Access 2020, 8, 153941-153955. [CrossRef]

5. Vinnikov, D.; Kosenko, R.; Chub, A.; Liivik, E. Shade-tolerant photovoltaic microinverter with time adaptive seamless P-V curve sweep MPPT. In Proceedings of the 2017 19th European Conference on Power Electronics and Applications (EPE'17 ECCE Europe), Warsaw, Poland, 11-14 September 2017; pp. 1-8. [CrossRef]

6. Enphase IQ 7, IQ 7+, and IQ 7X Microinverter Datasheet. Available online: https://enphase.com (accessed on 27 October 2020).

7. LaBella, T.; Yu, W.; Lai, J.; Senesky, M.; Anderson, D. A Bidirectional-Switch-Based Wide-Input Range High-Efficiency Isolated Resonant Converter for Photovoltaic Applications. IEEE Trans. Power Electron. 2014, 29, 3473-3484. [CrossRef]

8. Zhao, X.; Zhang, L.; Born, R.; Lai, J. A High-Efficiency Hybrid Resonant Converter With Wide-Input Regulation for Photovoltaic Applications. IEEE Trans. Ind. Electron. 2017, 64, 3684-3695. [CrossRef]

9. Kim, S.; Kim, B.; Kwon, B.; Kim, M. An Active Voltage-Doubler Rectifier Based Hybrid Resonant DC/DC Converter for Wide-Input-Range Thermoelectric Power Generation. IEEE Trans. Power Electron. 2018, 33, 9470-9481. [CrossRef]

10. Chub, A.; Vinnikov, D.; Lai, J. Input Voltage Range Extension Methods in the Series-Resonant DC-DC Converters. In Proceedings of the 2019 IEEE 15th Brazilian Power Electronics Conference and 5th IEEE Southern Power Electronics Conference (COBEP/SPEC), Santos, Brazil, 1-4 December 2019; pp. 1-6.

11. Vinnikov, D.; Chub, A.; Liivik, E.; Roasto, I. High-Performance Quasi-Z-Source Series Resonant DC-DC Converter for Photovoltaic Module-Level Power Electronics Applications. IEEE Trans. Power Electron. 2017, 32, 3634-3650. [CrossRef]

12. Vinnikov, D.; Chub, A.; Kosenko, R.; Zakis, J.; Liivik, E. Comparison of Performance of Phase-Shift and Asymmetrical Pulsewidth Modulation Techniques for the Novel Galvanically Isolated Buck-Boost DC-DC Converter for Photovoltaic Applications. IEEE J. Emerg. Sel. Top. Power Electron. 2017, 5, 624-637. [CrossRef]

13. Cha, H.; Peng, F.Z.; Yoo, D. Z-source resonant DC-DC converter for wide input voltage and load variation. In Proceedings of the 2010 International Power Electronics Conference-ECCE ASIA, Sapporo, Japan, 21-24 June 2010; pp. 995-1000. [CrossRef]

14. Loef, C.; de Doncker, R.W. An efficiency-optimized mode of operation for a resonant dc-dc converter with extended input voltage range for solar applications in dc-microgrids: Using topology-morphing to improve converter efficiency. In Proceedings of the 2015 IEEE 6th International Symposium on Power Electronics for Distributed Generation Systems (PEDG), Aachen, Germany, 22-25 June 2015; pp. 1-6. [CrossRef]

15. Jovanović, M.M.; Irving, B.T. On-the-Fly Topology-Morphing Control-Efficiency Optimization Method for LLC Resonant Converters Operating in Wide Input- and/or Output-Voltage Range. IEEE Trans. Power Electron. 2016, 31, 2596-2608. [CrossRef]

16. Kapat, S.; Patra, A.; Banerjee, S. Achieving Monotonic Variation of Spectral Composition in DC-DC Converters Using Pulse Skipping Modulation. IEEE Trans. Circuits Syst. I Regul. Pap. 2011, 58, 1958-1966. [CrossRef]

17. Chub, A.; Vinnikov, D.; Liivik, E.; Jalakas, T. Multiphase Quasi-Z-Source DC-DC Converters for Residential Distributed Generation Systems. IEEE Trans. Ind. Electron. 2018, 65, 8361-8371. [CrossRef]

18. Graovac, D.; Purschel, M.; Kiep, A. MOSFET Power Losses Calculation Using the Data-Sheet Parameters. Automotive Power, Application Note, Version. 1.1 2006. Available online: https://application-notes.digchip. com/070/70-41484.pdf (accessed on 14 October 2020).

19. Wong, S.C.; Brown, A.D.; Lee, Y.S.; Ng, S.W. Parasitic losses modeling of a series resonant converter circuit. In Proceedings of the 1997 IEEE International Symposium on Circuits and Systems (ISCAS), Hong Kong, China, 9-12 June 1997; Volume 2, pp. 921-924. [CrossRef] 
20. Zhang, D.; Zhang, Q.; Grishina, A.; Amirahmadi, A.; Hu, H.; Shen, J.; Batarseh, I. A Comparison of Soft and Hard-Switching Losses in Three Phase Micro-Inverters. In Proceedings of the 2011 IEEE Energy Conversion Congress and Exposition (ECCE), Phoenix, AZ, USA, 17-22 September 2011; pp. 1076-1082.

21. Venkatachalam, K.; Sullivan, C.R.; Abdallah, T.; Tacca, H. Accurate prediction of ferrite core loss with nonsinusoidal waveforms using only Steinmetz parameters. In Proceedings of the IEEE Workshop on Computers in Power Electronics 2002, Mayaguez, PR, USA, 3-4 June 2002; pp. 36-41.

22. Yue, S.; Li, Y.; Yang, Q.; Yu, X.; Zhang, C. Comparative Analysis of Core Loss Calculation Methods for Magnetic Materials Under Nonsinusoidal Excitations. IEEE Trans. Magn. 2018, 54, 6300605. [CrossRef]

23. Vishay. IHLP Inductor Loss Calculator Tool. Available online: http://www.vishay.com/inductors/calculator/ calculator/ (accessed on 14 October 2020).

24. West Coast Magnetics. Power Inductors. Available online: https://wcmagnetics.com/power-inductors/ (accessed on 14 October 2020).

25. CoilCraft. DC-DC Optimiser. Available online: https://www.coilcraft.com/apps/power_tools/dc-dc/ (accessed on 14 October 2020).

26. STMicroelectronics. Datasheet-STW45NM50FD. Available online: https://www.st.com/resource/en/ datasheet/CD00002477.pdf (accessed on 14 October 2020).

27. STMicroelectronics. Datasheet-SCT30N120. Available online: https://www.st.com/resource/en/datasheet/ sct30n120.pdf (accessed on 14 October 2020).

28. International Rectifier. Datasheet-IRF3805. Available online: http://www.irf.com/product-info/datasheets/ data/irf3805.pdf (accessed on 14 October 2020).

29. Ioannou, S.; Marouchos, C.; Darwish, M.; Putrus, G.A. Efficiency Investigation of A Protection and Correction Solid State Device for Low-Voltage Distribution Networks. In Proceedings of the 2019 54th International Universities Power Engineering Conference (UPEC), Bucharest, Romania, 3-6 September 2019; pp. 1-6. [CrossRef]

30. Ioannou, S.; Argyrou, M.C.; Marouchos, C.C.; Darwish, M. Efficiency Investigation of a Grid Connected PV System with Power Smoothing. In Proceedings of the 2019 54th International Universities Power Engineering Conference (UPEC), Bucharest, Romania, 3-6 September 2019; pp. 1-6. [CrossRef]

31. PowerSim Inc. PSIM-User's Guide. 2017. Available online: https://powersimtech.com/products/psim/ thermal. (accessed on 21 October 2020).

32. Ferroxcube. 3C95-Material specification. Available online: https://www.ferroxcube.com/upload/media/ product/file/MDS/3c95.pdf (accessed on 23 September 2020).

33. OnSemi. FDMS86180. Available online: https:/www.onsemi.com/products/discretes-drivers/mosfets/ fdms 86180 (accessed on 23 September 2020).

34. Ferroxcube. Software Design Tool (SFDT 2010). Available online: https://www.ferroxcube.com/upload/ media/design/sfdtsetup.zip (accessed on 27 October 2020).

Publisher's Note: MDPI stays neutral with regard to jurisdictional claims in published maps and institutional affiliations.

(C) 2020 by the authors. Licensee MDPI, Basel, Switzerland. This article is an open access article distributed under the terms and conditions of the Creative Commons Attribution (CC BY) license (http://creativecommons.org/licenses/by/4.0/). 